\title{
Pancreatic function and gene deletion F508 in cystic fibrosis
}

Graziella Borgo, Gianni Mastella, Paolo Gasparini, Antonella Zorzanello, Roberta Doro, Pier Franco Pignatti

\begin{abstract}
In view of the possible relation between pancreatic function and cystic fibrosis (CF) gene mutations, a detailed study on Italian patients was performed. Seventy pancreatic insufficient and $\mathbf{4 8}$ pancreatic sufficient patients were included after very accurate characterisation of their pancreatic and digestive function, all performed in the same $\mathrm{CF}$ centre. The CF gene deletion F508 was tested to define the patients' genotypes.

The results confirm that the mutation correlates with pancreatic insufficiency, and is recessive to other, as yet unreported, mutant alleles that determine pancreatic sufficiency. An indication that duodenal bicarbonate output is more severely reduced in the presence of deletion F508 is also presented. The data are discussed in relation to a hypothesis on the primary effects of CF gene deletion F508.
\end{abstract}

Cystic fibrosis (CF) is the most common genetic disease in the Caucasian population; it is inherited as an autosomal recessive trait and the estimated carrier frequency is about 1:22.

All patients show a raised electrolyte concentration in sweat, even though the clinical expression of the disease is heterogeneous. Obstructive lung disease and pancreatic insufficiency are the main clinical

Centro Regionale Veneto Fibrosi Cistica, Ospedale Civile Maggiore, Piazzale Stefani, 37126 Verona, Italy.

G Borgo, G Mastella, A Zorzanello, R Doro

Istituto di Scienze Biologiche, Facoltà di Medicina e Chirurgia, Università di Verona, Italy.

P Gasparini, P F Pignatti

Correspondence to Dr Borgo.

Received for publication 15 May 1990

Accepted for publication 7 June 1990. features. About $15 \%$ of patients have sufficient pancreatic function for normal digestion and do not require pancreatic enzyme supplementation.

Genetic linkage studies have mapped the CF locus to chromosome $7 .^{1-3}$ Several DNA markers, including KM19, XV2c, and MP6d9, ${ }^{4}$ are tightly linked to the CF locus. The CF gene has recently been identified and a deletion of three base pairs described, ${ }^{6-8}$ which results in the loss of a phenylalanine residue at position $508(\triangle F 508)$ of the putative product of the CF gene.

In North American CF patients, from $68 \%{ }^{6}$ to $76 \%{ }^{9}$ of the chromosomes show the deletion.

On the basis of extended DNA marker haplotype analysis of the CF locus, at least seven additional putative mutations have been indicated ${ }^{6}$ and the number of identified mutations has already increased beyond this ${ }^{10}$ (CF Genetic Analysis Consortium, personal communication).

Determination of deletion F508 in pancreatic sufficient (PS) and pancreatic insufficient (PI) patients provided strong support for the hypothesis that pancreatic insufficiency is the result of the presence of two 'severe' alleles, deletion F508 belonging to this category.

Pancreatic sufficiency in turn has been attributed to the presence of at least one mild allele, dominant over the 'severe' ones. This hypothesis was derived from a limited number (39 PI and 21 PS) of North American patients. $^{6}$

Published data about Italian CF haplotypes ${ }^{11} 12$ and their relation to PS and PI are available, ${ }^{13} 14$ derived from collaborative studies from different $\mathrm{CF}$ centres. These data may be further expanded as follows. (1) The frequency of deletion F508 is much lower in the Italian population. ${ }^{15-17}(2)$ The haplotype frequencies vary in different Italian regions. ${ }^{18}$ (3) The ascertainment of the clinical condition may have been based on rather varying criteria (different criteria for determination of pancreatic function have been used in previous studies). 
For all these reasons, and in order to perform a more precise clinical study, we have collected a large series of CF patients and studied the distribution of deletion F508 in subjects with pancreatic sufficiency or insufficiency, after assessment of pancreatic and digestive function performed in the same CF centre, according to strict and identical evaluation criteria.

\section{Subjects and methods PATIENTS}

A total of $123 \mathrm{CF}$ patients, 67 males and 56 females, referred to the Verona CF centre, was studied. The mean age at the time of the last follow up was 14 years (SD 8, range 0.9 to 34 years). CF diagnosis was based on sweat tests performed according to Gibson and Cooke, ${ }^{19}$ and confirmed by typical clinical pulmonary or gastrointestinal findings.

\section{ASSESSMENT OF PANCREATIC FUNCTION}

Exocrine pancreatic secretory function was assessed according to the following criteria. (1) Direct study of pancreatic function by duodenal intubation and pancreatic stimulation test (pancreozymin and secretin bolus $2 \mathrm{U} / \mathrm{kg}$ body weight). Output over 30 $\mathrm{min} / \mathrm{kg}$ body weight of bicarbonate (gasanalytic method), trypsin, chymotrypsin, and lipase (titrimetric method) ${ }^{20}$ was determined in 89 patients, including 44 of 48 PS patients. (2) Measurement of faecal chymotrypsin (kit Boeringwerke Biochemia, Mannheim Monotest Chymotrypsin) was performed in 73 patients. (3) Determination of serum levels of immunoreactive trypsin (IRT, kit Sorin-Biomedin, Saluzzo, Italy) was performed in 48 cases.

\section{DIGESTIVE FUNCTION ANALYSIS}

Fat digestion was studied using the following tests. (1) Three day fat balance with analysis of faecal fat according to Van De Kamer's method, as modified by Jeejeebhoy $e t a l^{21}$ for medium chain triglyceride fats. The coefficient of fat absorption was calculated in 99 cases. (2) Twenty four hour fat loss (using the method of Van De Kamer) ${ }^{21}$ was measured in 11 patients. (3) Steatocrit (according to Phuapradit et al ${ }^{22}$ was performed on duplicate faecal specimens in 105 cases.

\section{DEFINITION OF PANCREATIC SUFFICIENCY}

For the purpose of this study, patients were defined as pancreatic sufficient (PS) if they presented with: pancreatic enzyme output greater than the first centile of our own laboratory reference values ${ }^{23}$; faecal chymotrypsin $>5 \mathrm{U} / \mathrm{g}^{24}$; fat absorption coefficient $\geqslant 92 \%$; 24 hour steatorrhoea $<4 \mathrm{~g}$; IRT at normal or high levels (normal value 12 to $24 \mu \mathrm{g} / \mathrm{l}$ ); steatocriø $\leqslant 3 \%$.

As pancreatic dysfunction in CF is partly age related, and in most patients pancreatic structure ands function is well established after the second year of life, only patients in whom pancreatic sufficiency waspresent after this age were entered into the study.

DEFINITION OF PANCREATIC INSUFFICIENCY

Pancreatic insufficiency (PI) was defined on the basis $\overrightarrow{0}$ of: at least two determinations of pancreatic enzyme $\vec{A}$ output lower or equal to the first centile of the reference values ${ }^{23}$; faecal chymotrypsin absent or lower than $3 \mathrm{U} / \mathrm{g}$ faeces (duplicate specimens from ato least two samples); fat absorption coefficient $<90 \%$; N 24 hour steatorrhoea $\geqslant 4 \mathrm{~g}$; serum IRT absent or lower than the first centile of the reference values; $;$ steatocrit $\geqslant 10 \%$. The ascertainment of pancreatic insufficiency was considered at whatever age it waso performed, on the assumption that the pancreatic insufficiency in CF is irreversible.

\section{FINAL CLASSIFICATION OF PANCREATIC FUNCTION}

In the evaluation of pancreatic sufficiency or insufficiency in each case, all the available results wege $\overrightarrow{0}$ considered. A decreasing value was assigned to the? above criteria according to their order.

Patients assumed to have pancreatic sufficiency the basis of retrospective data were all checked between October and December 1989 before being entered into the study.

The final judgement on pancreatic function was then based on the comprehensive evaluation of both pancreatic and digestive parameters. Patients were defined as pancreatic sufficient only if they showed retrospective normal values, confirmed by at least two tests of pancreatic function (usually faecal chymotrypsin and serum immunoreactive trypsin) and at least one test of digestive function (usually steatocrit 3 or 24 hour steathorroea) at the latest check up.

\section{DNA ANALYSIS}

Genomic DNA was prepared from whole blood by음 standard methods. Deletion F508 was detected, after DNA amplification, by polyacrylamide gel electro- $\sim$ phoresis or by oligonucleotide hybridisation or $\mathrm{N}$ both. 1516

\section{STATISTICAL EVALUATION}

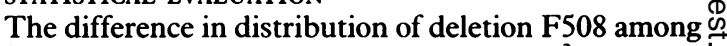
PS and PI patients was evaluated by the $\chi^{2}$ test. The means of the results of pancreatic bicarbonate output in duodenal fluid, assuming the distribution of 
bicarbonate values in PI and PS groups to be nonparametric, were compared using the Mann-Whitney test. $^{25}$

\section{Results}

A total of 123 patients was initially included in the study, as detailed in the Methods section. On retrospective analysis, 64 were defined as pancreatic insufficient and 59 as pancreatic sufficient. Six of the latter had developed pancreatic insufficiency within the period of time from the first evaluation to the follow up (from 2.2 to 8.6 years), so they were transferred to the pancreatic insufficient group.

Two pancreatic sufficient patients did not present to follow up and were excluded from the study. Three subjects who did not have pancreatic enzyme replacement showed conflicting laboratory results, and were thought to have borderline pancreatic sufficiency, so were excluded. Therefore, the final total in the study included 48 confirmed pancreatic sufficient and 70 pancreatic insufficient patients.

Tabie 1 Distribution of $\triangle F 508$ in CF-PS and PI patients.

\begin{tabular}{lcc}
\hline & Total chromosomes & $\begin{array}{c}\text { Chromosomes with } \\
\text { the deletion } \\
(n=236)\end{array}$ \\
\hline PS patients $(n=48)$ & 96 & $25(26 \%)$ \\
PI patients $(n=70)$ & 140 & $58(41 \%)$ \\
\hline
\end{tabular}

$\triangle F 508=$ deletion phenylalanine 508 . PS=pancreatic sufficient. $\mathrm{PI}=$ pancreatic insufficient. $\chi^{2}=5 \cdot 91, \mathrm{p}=0.015$.

Table 2 Distribution of $\triangle F 508$ genotypes in CF-PS and PI patients.

\begin{tabular}{lcc}
\hline Genotype & PS patients $(\mathbf{n}=48)$ & PI patients $(\mathbf{n}=70)$ \\
\hline$\triangle \mathrm{F} 508 / \triangle \mathrm{F} 508$ & 0 & $11(16 \%)$ \\
$\triangle \mathrm{F} 508 / \mathrm{U}$ & $25(52 \%)$ & $36(51 \%)$ \\
$\mathrm{U} / \mathrm{U}$ & $23(48 \%)$ & $23(33 \%)$ \\
\hline
\end{tabular}

$\mathrm{U}=$ other uncharacterised mutation.
The presence of deletion F508 was investigated in all patients. It was present in $26 \%$ of CF-PS chromosomes, and in $41 \%$ of CF-PI chromosomes, in agreement with our previous reports. ${ }^{15} 16$ Different, still uncharacterised, mutations must therefore be carried by $74 \%$ of PS and by $59 \%$ of PI chromosomes (table 1). This difference is significant $\left(\chi^{2} 5 \cdot 91\right.$, $\mathrm{p}=0.015$ ). Among PS patients, $52 \%$ were heterozygous and none homozygous for deletion F508. Among PI patients, $51 \%$ were heterozygous and $16 \%$ homozygous for the mutation (table 2).

We then considered the hypothesis of Kerem et at that pancreatic sufficiency may be the result of the presence of 'mild' (M) alleles which produce a dominant phenotype with residual exocrine function. 'Severe' alleles, including deletion F508, would on the other hand express little or no pancreatic function.

The observed genotype frequencies of CF-PI and CF-PS patients are shown in table 3 , together with the frequencies predicted on the basis of the model mentioned above, and on the assumption of HardyWeinberg equilibrium in the population. The total frequency of severe alleles was deducted from the observed proportion of CF-PI patients in our centre: $(0 \cdot 85)^{1 / 2}=0.922$.

The observed frequency of deletion F508 in the total $C F$ population attending the centre is 0.404 . The frequency of $S$ alleles is therefore $0 \cdot 922-0 \cdot 404=0 \cdot 518$. The frequency of $M$ is $1-0.922=0.078$. The expected numbers of CF-PI and CF-PS patients were calculated after normalisation within each group. As shown in table 3, the observed frequencies are in agreement with the hypothesis, thus indicating that CF-PI patients carry two 'severe' alleles, while CF-PS patients carry at least one copy of a 'mild' mutation. These data also explain the higher frequency of deletion F508 in PI patients. The model of Kerem $e t$ $a l^{6}$ is therefore confirmed in the Italian population, where the frequency of deletion F508 is lower than in North American CF patients. ${ }^{15}$

Ductal pancreatic function of PS and PI patients

Table 3 Mild and severe alleles in CF-PI and PS patients according to Hardy-Weinberg equilibrium.

\begin{tabular}{|c|c|c|c|c|}
\hline Pancreatic function & Assumed genotype & Predicted frequency & $\begin{array}{l}\text { Observed No of } \\
\text { patients }\end{array}$ & $\begin{array}{l}\text { Expected No of } \\
\text { patients }\end{array}$ \\
\hline PI & $\begin{array}{c}\text { F,F } \\
\text { F,S } \\
\text { S,S } \\
\text { Total }\end{array}$ & $\begin{array}{l}0.163 \\
0.419 \\
0.268 \\
0.85\end{array}$ & $\begin{array}{l}11 \\
36 \\
23 \\
70\end{array}$ & $\begin{array}{l}13 \cdot 4 \\
34 \cdot 5 \\
22 \cdot 1 \\
70\end{array}$ \\
\hline PS & $\begin{array}{c}M, F \\
M, S \\
M, M \\
\text { Total }\end{array}$ & $\begin{array}{l}0.063 \\
0.081 \\
0.006 \\
0.150\end{array}$ & $\begin{array}{l}25 \\
23\end{array}$ & $\begin{array}{c}20 \cdot 2 \\
25 \cdot 9 \\
1 \cdot 9 \\
48\end{array}$ \\
\hline
\end{tabular}

$S=$ uncharacterised severe mutant alleles. $M=$ uncharacterised mild mutant alleles.

The hypothesis ${ }^{6}$ and the calculations are detailed in the text.

$\chi_{2}^{2}$ PI patients $=0.532$ (NS).

$\chi^{2}$ PS patients $=1.97$ (NS).

$\chi^{2} \mathrm{PI}+\mathrm{PS}$ patients $=2 \cdot 502$ (NS). 
Table 4 Mean value of bicarbonate output by duodenal intubation and $\triangle F 508$ genotype in CF-PS and PI patients.

\begin{tabular}{|c|c|c|c|c|}
\hline \multirow[b]{2}{*}{ Genotype } & \multicolumn{2}{|r|}{ PS patients } & \multicolumn{2}{|r|}{ PI patients } \\
\hline & $\begin{array}{c}\text { No of } \\
\text { patients }\end{array}$ & $\begin{array}{l}\text { Bicarbonate output } \\
\text { mean value }(\mathrm{mEq} / \mathrm{kg} / 30 \mathrm{~min})\end{array}$ & $\begin{array}{l}\text { No of } \\
\text { patients }\end{array}$ & $\begin{array}{l}\text { Bicarbonate output } \\
\text { mean value }(\mathrm{mEq} / \mathrm{kg} / 30 \mathrm{~min})\end{array}$ \\
\hline $\begin{array}{l}\Delta F 508 / \Delta F 508 \\
\Delta F 508 / U \\
U / U\end{array}$ & $\begin{array}{r}0 \\
23 \\
21\end{array}$ & $\begin{array}{l}34.86(\overline{S D} 29 \cdot 46) \\
25.79(\text { SD } 29 \cdot 97)\end{array}$ & $\begin{array}{r}6 \\
26 \\
13\end{array}$ & $\begin{array}{l}4 \cdot 19 \text { (SD } 4 \cdot 20) \\
5 \cdot 24 \text { (SD } 5 \cdot 24) \\
9 \cdot 2 \quad(\text { SD } 8 \cdot 99)\end{array}$ \\
\hline
\end{tabular}

was evaluated by measuring the duodenal bicarbonate output. A wide range of values resulted from the study of $45 \mathrm{PI}$ and $44 \mathrm{PS}$. The mean value in PI was 6.24 (SD 6.59) $\mathrm{mEq} / \mathrm{kg} / 30 \mathrm{~min}$ and in PS 29.35 (SD $29 \cdot 22)$.

Bicarbonate output was compared with genotypes (table 4). No significant difference was evident, even though it was observed that in the PI patient group deletion F508 homozygotes had a mean value of $4 \cdot 19$, deletion F508 heterozygotes $5 \cdot 24$, and patients with an unknown mutation(s) $\mathbf{9} \cdot \mathbf{2}$. Comparison between $\Delta$ F508 homozygotes and other genotypes with the Mann-Whitney test gave $\mathrm{p}=0 \cdot 12$.

The observation that deletion F508 heterozygotes had a mean value of bicarbonate output of 34.8 in PS patients and $5 \cdot 2$ in PI patients indicates that uncharacterised mild mutant alleles show dominant effects on duodenal bicarbonate output in the same way as indicated above for pancreatic enzyme secretion.

\section{Discussion}

The accurate characterisation of pancreatic function is an important aspect of this report. Unfortunately, the exocrine pancreas is difficult to study, because the organ and its secretions are inaccessible for anatomical reasons. For this reason many previous studies have been performed using patients assessed by indirect tests of pancreatic function, since they are less (or non) invasive and easier to perform. However, they are generally less specific and less sensitive, and measure features secondary to the pancreatic insufficiency which arise only when almost all the organ is destroyed. It has been shown that very little residual pancreatic function is sufficient to prevent fat malabsorption $^{26} 27$ and that non-pancreatic factors (mainly lingual lipase) may control the degree of steatorrhoea. $^{28}$

For the above reasons, the attribution of normal pancreatic function to $\mathrm{CF}$ patients not requiring pancreatic enzyme supplementation, or having normal digestive function tests, may lead to an inaccurate assessment of the patients. In the present study, these criteria were therefore never used alone to classify CF patients, as they are insufficient for an accurate evaluation of pancreatic function.

Another aspect to be underlined is the progression of pancreatic damage with age. Waters et $a l^{29}$ have shown that up to $38 \%$ of CF infants screened in the $\overrightarrow{0}$ neonatal period show pancreatic sufficiency and $\vec{\longrightarrow}$ evidence of normal fat digestion, while in many of $\vec{\omega}$ them pancreatic insufficiency is expected to develop with advancing age. Cross sectional analysis of large CF populations in fact usually reveals pancreatic N sufficiency only in $15 \%$ of CF patients. For this reason, we excluded from our study patients evaluated for pancreatic function under 2 years of age. No patient was assigned to the pancreatic sufficient group $O$ without a recent (less than three months) reassessment. In spite of our efforts to separate strictly pancreatic sufficient from insufficient patients, three of them remained unclassified, as conflicting results were obtained from pancreatic and digestive function tests.

In well characterised patients, deletion F508 has a different frequency in pancreatic sufficient and in sufficient patients. Our data confirm the hypothesis that it is a mutation conferring a 'severe' pancreatic. phenotype, and that it is recessive to 'mild' mutations conferring normal or slight pancreatic function. Only pancreatic insufficient patients carry two copies of the deletion while pancreatic sufficient patients always carry at least one 'mild' unknown CF allele.

It is noteworthy that the hypothesis of Kerem et al agrees in particular with this sample of the Italian population, in which the frequency of deletion F508 is much lower than in the North American population they studied. Our opinion about the reported cases of deletion F508 homozygotes among PS patients ${ }^{30}$ is that their pancreatic function was probably questionably evaluated as normal.

Finally, it is interesting to consider in what way deletion F508 may influence pancreatic function. There is evidence that the basic alteration in CF is related to defective chloride transport. The CF gene predicted protein product CFTR is likely to be involved in the transport of ions across the cell membrane, as an ion channel itself or as a regulatory protein which controls the opening and 'gating' of an apical plasma membrane chloride channel. ${ }^{31}$

When the chloride channel opens, chloride exits through the membrane, followed by sodium, and finally by water secretion. A defective chloride channel would therefore lead to a diminished secretory volume.

Chloride dependent bicarbonate secretion was shown in CF pancreas, ${ }^{32}$ to which a deficiency of fluid 
secretion could be correlated. The diminished fluid secretion is present in the pancreas of CF patients at any given level of enzyme secretion, even those with good enzymatic output. Bicarbonate secretion might therefore be considered a primary phenomenon related to deletion F508.

However, there is some conflict in this sense in our study as in CF-PI patients there is less bicarbonate output when deletion F508 is present, and PI homozygotes for the deletion have the least output; such a tendency is not shown in PS patients. A possible bias in evaluating bicarbonate output is that it was measured in patients at different ages. Finally, the role of degenerative factors in local tissue in determining pancreatic disease, and possibly its rate of progression, is unknown. These factors may be related to the decreased fluid output and the consequent increased protein concentration, which may in turn predispose to ductal obstruction and progressive acinar destruction. ${ }^{33}$

In order to establish further how genetic factors may influence the degree of pancreatic disease in $\mathrm{CF}$, the effects of the still uncharacterised CF mutations need to be assessed.

We wish to thank Drs A Bonizzato and A Savoia for helpful collaboration, P Faggionato, A Facchin, and $\mathrm{R}$ Galavotti for skilful technical assistance and Drs S Lorenzini and $\mathrm{L}$ Zanolla for advice on statistical evaluations.

I Knowlton RG, Cohen-Haguenauer D, Van Cong N, et al. A polymorphic DNA marker linked to cystic fibrosis is located on chromosome 7. Nature 1985;318:380-2.

2 White R, Woodward S, Leppert $M$, et al. A closely linked genetic marker for cystic fibrosis. Nature 1985;318:382-4.

3 Wainwright BJ, Scambler PJ, Schmidtke J, et al. Localization of cystic fibrosis locus to human chromosome 7cen-q22. Nature 1985;318:384-5.

4 Estivill X, Scambler DJ, Wainwright BJ, et al. Patterns of polymorphisms and linkage disequilibrium for cystic fibrosis. Genomics 1987;1:257-63.

5 Estivill X, McLean C, Nunes V, et al. Isolation of a new DNA marker in linkage disequilibrium with cystic fibrosis, situated between J3.11 (D7S8) and JRP. Am f Hum Genet 1989;44: 704-10.

6 Kerem BS, Rommens JM, Buchanan A, et al. Identification of the cystic fibrosis gene: genetic analysis. Science 1989;245: 1073-80.

7 Rommens JM, Iannuzzi MC, Kerem BS, et al. Identification of the cystic fibrosis gene: chromosome walking and jumping. Science 1989;245:1059-65.

8 Riordan JR, Rommens JM, Kerem BS, et al. Identification of the cystic fibrosis gene: cloning and characterization of complementary DNA. Science 1989;245: 1066-72.

9 Lemna WK, Feldman GL, Kerem B, et al. Mutation analysis for heterozygote detection and the prenatal diagnosis of cystic fibrosis. N Engl f Med 1990;322:291-6.

10 Roberts L. CF screening delayed for a while, perhaps forever. Science 1990;247:1296-7.

11 Estivill X, Farrall M, Williamson R, et al. Linkage disequilibrium between cystic fibrosis and linked polymorphic DNA markers in Italian families: a collaborative study. Am $\mathcal{F ~ H u m ~ G e n e t ~}$ 1988;43:23-8

12 Estivill X, Gasparini P, Novelli G, et al. Linkage disequilibrium for DNA haplotypes near the cystic fibrosis locus in two South European populations. Hum Genet 1989;83:175-8.

13 Gasparini P, Novelli G, Estivill X, et al. The genotype of a new linked DNA marker, MP6d-9, is related to the clinical course of cystic fibrosis. 7 Med Genet 1990;27:17-20.

14 Ferrari M, Antonelli M, Bellini $F$, et al. Genetic differences in cystic fibrosis patients with and without pancreatic insufficiency: an Italian collaborative study. Hum Genet (in press).

15 Estivill X, Chillon M, Casals T, et al. DF508 gene deletion in cystic fibrosis in Southern Europe. Lancet 1989;ii: 1404.

16 Novelli G, Gasparini P, Savoia A, et al. Polymorphic DNA haplotypes and DF508 deletion in 212 Italian CF families. Hum Genet (in press).

17 The Cystic Fibrosis Genetic Analysis Consortium. Worldwide survey of the delta F508 mutation. Am f Hum Genet (in press).

18 Gasparini P, Cappello N, Dallapiccola B, et al. Regional distribution of cystic fibrosis linked DNA haplotypes in Italy, a collaborative study. Gene Geography (in press)

19 Gibson LE, Cooke RE. A test for concentration of electrolytes in sweat in cystic fibrosis of pancreas-utilizing pilocarpine by iontophoresis. Pediatrics 1959;23:545-51.

20 Figarella C, Taulier G, Sarles H. Dosage de la chymotrypsin et de la trypsin dans le suc duodenal. Bull Soc Chim Biol 1965;47: 679-84.

21 Jeejeebhoy KN, Ahmed S, Kozek G. Determination of fecal fats containing both medium and long chain triglycerides and fatty acids. Clin Biochem 1970;3:157-61.

22 Phuapradit P, Narang A, Mendonca P, et al. The steatocrit: a simple method for estimating stool fat content in newborn infants. Arch Dis Child 1981;56:725-7.

23 Mastella G, Barbato G, Trabucchi C, et al. The exocrine pancreas in cystic fibrosis. Functional studies in 169 patients and 118 controls. Ital f Pediatr 1975;1:109-30.

24 Girella E, Faggionato P, Benettazzo D, et al. The assay of chymotrypsin in stool as a simple and effective test of exocrine pancreatic activity in cystic fibrosis. Pancreas 1988;3:254-62.

25 Harmitage P. Statistical methods in medical research. Oxford Blackwell Scientific Publications, 1971.

26 Gaskin KJ, Durie PR, Lee L, et al. Colipase of patients with steathorrea secondary to relative colipase deficiency. Gastroenterology 1984;86:1-7.

27 Durie PR, Forstner G. Pathophysiology of the exocrine pancreas in cystic fibrosis. $7 R$ Soc Med 1989;82 (suppl 16): 1-10.

28 Fredrikson B, Blackberg L. Lingual lipase: an important lipase in the digestion of dietary lipids in cystic fibrosis? Pediatr Res 1980;14:1387-90.

29 Waters D, Dorney S, Gruca M, et al. Pancreatic sufficiency in CF infants from a neonatal screening programme. Proceedings of the 10th International Cystic Fibrosis Congress, Sydney, Australia. Amsterdam: Excerpta Medica 1988: series 74:162.

30 Stuhrmann M, Macek M, Reis A, et al. Genotype analysis of cystic fibrosis patients in relation to pancreatic sufficiency. Lancet 1990; i:738.

31 Quinton PM. Chloride impermeability in cystic fibrosis. Nature 1983;301:431-2.

32 Kopelman HR, Corey M, Gaskin KJ, et al. Impaired chloride secretion as well as bicarbonate secretion underlies the fluid secretory defect in the cystic fibrosis pancreas. Gastroenterology 1988;95:349-55.

33 Sturgess JM. Structural and developmental abnormalities of the exocrine pancreas in cystic fibrosis. Proceedings of the 5th Professional Conference of the Canadian Cystic Fibrosis Foundation. F Pediatr Gastroenterol Nutr 1984; suppl 1:S55-66. 